\title{
HERD BEHAVIOUR IN SOUTHEAST ASIAN STOCK MARKETS - AN EMPIRICAL INVESTIGATION*
}

\author{
Nha D. BUI - Loan T. B. NGUYEN - Nhung T. T. NGUYEN
}

(Received: 23 January 2014; revision received: 20 June 2014; accepted: 26 June 2014)

\begin{abstract}
This study examines herd behaviour in four Southeast Asian stock markets, namely Indonesia, the Philippines, Malaysia, and Vietnam. Empirical results indicate that except for the Philippines, herding exists in the other three markets. Stronger evidence of herding has been detected in these markets when the market is up. When the market is down, it is only the Malaysian market that exhibits significant herding. The study further investigates herding by dividing the entire sample period into two sub-periods: pre-crisis and during economic crisis. We find strong evidence of the existence of herding in Indonesia and Malaysia in both sub-periods. However, the findings are mixed when we additionally examine herding in up and down market scenarios during the two sub-periods by using modified models.
\end{abstract}

Keywords: herding, emerging markets

JEL classification indices: C32, G11, G15

* The authors would like to thank Prof. Katalin Szabó, Prof. Balázs Hámori, and the two anonymous referees for their valuable comments and suggestions.

Nha D. Bui, Lecturer at the Finance and Banking Faculty, Ton Duc Thang University, Ho Chi Minh City, Vietnam. E-mail: buiducnha@tdt.edu.vn

Loan T. B. Nguyen, corresponding author. Dean at the Finance and Banking Faculty, Ton Duc Thang University, Ho Chi Minh City, Vietnam. E-mail: nguyenthibichloan@tdt.edu.vn

Nhung T. T. Nguyen, Lecturer at the Finance and Banking Faculty, Ton Duc Thang University, Ho Chi Minh City, Vietnam. E-mail: nguyenthituyetnhung@tdt.edu.vn 


\section{INTRODUCTION}

Since initially discussed in the famous study of Fama (1970), the efficient market hypothesis (EMH) has become an area of interest for portfolio and fund managers, brokers, investors as well as academic researchers in their attempt to test for the existence of market efficiency. According to the EMH, a market is informationally efficient when any new information introduced into the market is immediately incorporated into future stock prices, and investors form rational expectations of future prices based on the information available in the market. Hence, all securities are correctly priced. However, reality and researchers have revealed that there are irrational investment behaviours that have caused abnormal losses and returns in the market. Among these, herding is one such abnormal behaviour, which strongly challenges the validity of the EMH. Herding refers to the case whereby investors do not make investment decisions based on their rational analysis, but by following the actions of others. Christie - Huang (1995) argued that this could be a consequence of social pressure and the common logic that crowds can not be wrong and are better informed than individual investors. As a result, herd behaviour may destabilise the market by driving stocks' prices away from their fundamental value, hence causing market inefficiency.

Motivated by the important implications of herding for both practitioners and academics, numerous works have been conducted and mixed evidence of herding has been found in many developed and emerging financial markets. Therefore, in this paper, we extend the extant researches by investigating the presence of herding in four Southeast Asian stock markets, namely Indonesia, Malaysia, the Philippines, and Vietnam. ${ }^{1}$ Although studies of herding have been performed in those markets, the results of this study are expected to further contribute to the herding debate especially by detecting herd behaviour in pre-crisis and crisis periods, and by searching for the reason behind the existence or non-existence of this behaviour. The findings of this study will therefore enhance our understanding of herding in the literature, in addition to helping investors recognise the potential risks and guiding them to employ appropriate strategies while investing in these markets.

The remainder of the study is organised as follows. Section 2 briefly provides an empirical review of herding behaviour. Section 3 describes the data and methodology utilized, while the empirical findings are presented and discussed in Section 4 . Section 5 provides a summary and our conclusions.

1 The four countries are chosen due to the data availability during the sample period. It is also noted that other equity markets in the Southeast Asian region, namely Laos, Cambodia, Myanmar, Brunei, and East Timor are newly established; Singapore's equity market is extremely developed, hence we chose to omit it from this study. 


\section{LITERATURE REVIEW}

Herding can be classified into two major forms, including irrational and rational herding. As defined by Christie - Huang (1995), irrational herding refers to the tendency whereby individuals irrationally ignore their beliefs and analytical skills, and solely make their investment decisions based on the actions of the whole market, even when they perceive the market's prediction to be wrong. According to Vaughan - Hogg (2005), a possible explanation is that imitating the market's actions will relieve investors' uncertainty and make them feel more confident in their decision-making process.

On the other hand, the rational view mainly focuses on a scenario where herding occurs as the result of the principal-agent problem, in which managers follow the actions of other managers; low skill managers in particular tend to mimic good skill managers. In this case, the managers entirely disregard their own private information in order to hold their reputation in the market (Scharfstein Stein 1990; Rajan 1994). Rational herding may also occur among individual investors. They may rationally follow other investors whom they believe to have access to unpublicised information in the market with high confidence that their performance will not be below the market average (Demirer - Kutan 2006). In short, both explanations of herd behaviour essentially imply that investors do not make their investment decisions based on their own analysis and information, but rather follow the market consensus.

Numerous papers have investigated the existence of herding in global financial markets, but the results are mixed. Christie - Huang (1995) employed the cross-sectional standard deviation of returns to capture herd behaviour and they reported no evidence of herding in US markets as shares' return dispersion increases instead of decreasing during periods of extreme price movements. In the study of Chang et al. (2000), no significant degree of herding was found in developed financial markets such as the US, Hong Kong and Japan. In contrast, Nofsinger - Sias (1990) reported that a high degree of herding actually exists in the US market, particularly among institutional investors. Iihara et al. (2001) found that Japanese individual and institutional investors are more likely to herd, but foreign investors' investment decisions were based on the available information in the market. In a recent study by Chiang - Zheng (2010), daily data from May 25, 1988 to April 24, 2009 was employed and significant evidence of herding was found in numerous markets including Australia, France, Germany, Hong Kong, Japan, the UK, Argentina, Brazil, Chile, Mexico, and other Asian markets such as China, South Korea, Taiwan, Indonesia, Malaysia, Singapore, and Thailand. The results challenge the earlier literature, which found no herding in those markets. 
In contrast to developed financial markets where less evidence of herding is observed, empirical research investigating emerging markets reports high levels of herding, especially in Asian markets. A potential explanation for this observation is based on the market inefficiencies in these countries, which have traditionally been characterised by unsophisticated retail investors, a high degree of government intervention, and insufficient requirements relating to information disclosure of listed companies (Yuan et al. 2014). Besides the findings of Chiang - Zheng (2010) mentioned above, other studies also found significant herding in emerging markets. Chang et al. (2000) found a non-linear relationship between daily cross-sectional absolute deviation and the corresponding equally-weighted market return for South Korea and Taiwan, and hence concluded the existence of herding in these two markets. They suggested that herd behaviour may be the result of frequent government intervention, the existence of inefficient information disclosure, and the presence of more speculators in these markets. By further examining the role of macroeconomic and firm-specific information in the markets exhibiting herd behaviour, they noted that, interestingly, macroeconomic information tends to have a greater impact on market participants. ${ }^{2}$ Chiang et al. (2010) used the least squares method to investigate herding in Chinese stock markets and found that both Shanghai and Shenzhen A-share markets exhibit herd behaviour, but B-share investors behave differently. They explain that B-share investors are mostly foreign and institutional investors who have access to diverse information and more sophisticated techniques and are thus more rational in making investment decisions. However, the empirical results also show that B-share investors tend to herd in down markets due to their uncertainty regarding the Chinese government's frequent interventions. The authors explain that B-share investors intentionally consider the Chinese government's interventions as a market risk due to their less knowledge and experience with the government's policies. Therefore, these investors are more concerned about this uncertainty, especially in a down market. As a result, B-share investors are likely to herd in a down market.

Lao - Singh (2011) found that herding is present in both Chinese and Indian markets, with different herding patterns arising in each. A recent study by Bhaduri - Mahapatra (2013) also identified consistent patterns of herd behaviour in Indian equity markets. The presence of herding is also pronounced in other Asian equity markets such as Taiwan (Demirer et al. 2010), Malaysia (Duasa -

2 Cheng et al. (2000) explained that a relative insufficiency of timely and accurate firm-related information in emerging countries may cause investors to seek trading signals from macroeconomic information, which as a result play a significant role in the investment decisions of investors. 
Kassim 2008), Taiwan, China, South Korea, Singapore, Hong Kong, and Japan (Laih - Lau 2013), and China, Indonesia, Malaysia, and Thailand (Chiang et al. 2013).

\section{METHODOLOGY AND DATA}

\subsection{Methodology}

We followed the methodology proposed by Chang et al. (2000). This methodology basically utilises the cross-sectional dispersion of individual stock returns measured by the cross-sectional average dispersion (CSAD), which statistically is defined as:

$$
C S A D_{t}=\frac{1}{n}\left|r_{i, t}-r_{m, t}\right|
$$

where $r_{i, t}$ is the daily logarithmic return for underlying asset $i, r_{m, t}$ is the equally weighted average return on the market portfolio for period $t$, and $n$ is the number of stocks in the portfolio.

According to Chang et al. (2000), the rational asset pricing model implies that the level of equity return dispersions will increase when the absolute value of overall market returns increases since volatility increases. In other words, there is a positive linear relationship between CSAD and market returns. However, if investors try to follow the market movement and intentionally ignore their own preferences during periods of extreme price volatility, then the relationship between dispersion and market returns can increase at a decreasing rate, or even decrease if herding is severe.

To formally test for herding, Chang et al. (2000) adopt the following regression model:

$$
\begin{array}{ll}
C S A D_{t}^{U P}=\alpha+\gamma_{1}^{U P}\left|R_{m, t}^{U P}\right|+\gamma_{2}^{U P}\left(R_{m, t}^{U P}\right)^{2}+\varepsilon_{t} & \text { if } R_{m, t}>0(2 \mathrm{a}) \\
C S A D_{t}^{\text {DOWN }}=\alpha+\gamma_{1}^{D O W N}\left|R_{m, t}^{\text {DOWN }}\right|+\gamma_{2}^{D O W N}\left(R_{m, t}^{D O W N}\right)^{2}+\varepsilon_{t} & \text { if } R_{m, t}<0(2 \mathrm{~b})
\end{array}
$$

where $\left|R_{m, t}^{D O W N}\right|,\left|R_{m, t}^{U P}\right|$ are the absolute values of an equally weighted realised return of all available securities on day $t$ when the market is up or down, and $\left(R_{m, t}^{D O W N}\right)^{2},\left(R_{m, t}^{U P}\right)^{2}$ are the squared values of these terms. Under this model, if no herding activity exists in the market and the rational asset pricing model holds, the regression should demonstrate linearity, implying that $\gamma_{2}=0$. In contrast, 
a non-linear equation with a statistically significantly negative $\gamma_{2}$ indicates the presence of herding.

Since a high level of serial autocorrelation is expected to exist in high frequency time-series market data, the failure to exactly address this problem will result in biased estimates of the parameters. Consequently, in addition to employing the heteroscedasticity and autocorrelation consistent standard errors suggested by Newey - West (1987) to estimate the regression coefficients, we modified the models by using a 1-day lag of the dependent variable $\left(\mathrm{CSAD}_{t}\right)$ and the independent variable $\left(R_{m, l}\right)$ to improve the power of the empirical model as follows:

$$
C S A D_{t}^{U P}=\alpha+\gamma_{1}^{U P}\left|R_{m, t}^{U P}\right|+\gamma_{2}^{U P}\left(R_{m, t}^{U P}\right)^{2}+\gamma_{3}^{U P}\left(R_{m, t-1}^{U P}\right)^{2}+\gamma_{4}^{U P} C S A D_{t-1}^{U P}+\varepsilon_{t}
$$

if $R_{m, t}>0$

$C S A D_{t}^{\text {DOWN }}=\alpha+\gamma_{1}^{\text {DOWN }}\left|R_{m, t}^{\text {DOWN }}\right|+\gamma_{2}^{\text {DOWN }}\left(R_{m, t}^{\text {DOWN }}\right)^{2}+\gamma_{3}^{\text {DOWN }}\left(R_{m, t-1}^{D O W N}\right)^{2}+\gamma_{4}^{D O W N} C S A D_{t-}^{L}$

if $R_{m, t}<0$

In these two models, the existence of herd behaviour can be confirmed if $\gamma_{2}$ or $\gamma_{3}$ is statistically significantly negative and the sum of $\gamma_{2}+\gamma_{3}$ is also negative. If $\gamma_{2}$ and $\gamma_{3}$ are simultaneously negative, the degree of herding is extremely strong.

We observe a significant difference in the estimated results between equations (2a), (2b) and (3a), (3b). In Indonesia, herding does not exist when the market is down. Conversely, when the market is up, evidence of herding is found in both the pre-crisis and the crisis period. This strongly indicates that the level of equity return dispersions is not only dependent on market return at date $t$, but also affected by the return (up or down) of the previous trading day. This indicates that individual investors tend to mimic the actions of the market when the market is up. During the period when the market is down, investors are likely to make their own investment decisions based on available information, indicating no existence of herding.

\subsection{Data}

Daily closing stock prices were obtained for the period from February 25, 1997 to August 28, 2013 for Indonesia (IN), from April 14, 1992 to August 28, 2013 for Malaysia (MA), from December 16, 2003 to August 28, 2013 for the Philippines (PH), and from January 10, 2007 to August 28, 2013 for Vietnam (VI). From each market, we collect historical data for all blue-chip stocks that comprised the 
market's main stock index on August 28, 2013. The choice of the starting date is constrained by the availability of the data. In addition, it is important to note that any underlying stock with a trading period of less than one year up to August 28, 2013 was eliminated from our samples. Therefore, our final sample data include 30 stocks for Vietnam, 27 stocks for the Philippines, 29 stocks for Malaysia, and 30 stocks for Indonesia. Besides, to examine the existence of herding during the economic crisis, we divide the entire sample period into two sub-periods: a pre-crisis period, which extends to and includes December 31, 2006, and a crisis period, which extends from December 31, 2006 onwards. However, we only investigate herding in the two sub-periods for the Philippines, Indonesia, and Malaysia. Sample data for Vietnam's stock market is only collected from December 31, 2006 onwards due to the market accommodating a very small number of listed stocks and correspondingly low trading volumes prior to $2006 .{ }^{3}$

All data were obtained from Bloomberg and daily logarithmic returns are calculated as:

$$
r_{i, t}=\ln P_{i, t}-\ln P_{i, t-1}
$$

where $r_{i, t}$ is the daily logarithmic return for underlying asset $i$, and $P_{i, t}$ is the price of underlying asset $i$.

\section{EMPIRICAL RESULTS}

\subsection{Descriptive statistics}

Table 1 provides a descriptive statistics summary of CSAD variables corresponding to each market. Numbers of stocks range from 26 to 30 . By checking the mean values of CSAD, we find that Indonesia has higher mean values compared with those of the other markets. A comparison of the maximum and minimum values of the daily CSAD shows that Indonesia exhibits the highest (16.71\%) and the Philippines has the lowest values $(9.00 \%)$. All four time-series of CSAD appear to be highly autocorrelated. The first order autocorrelation of CSAD ranges from the lowest of 0.243 in the case of Vietnam to the highest of 0.729 for Malaysia. Therefore, all standard errors of the estimated regression coefficients in subsequent tests are adjusted for heteroscedasticity and autocorrelation, based on the approach suggested by Newey - West (1987). Moreover, the Unit root test

As of December 31, 2005, the Vietnam stock exchange had only 27 listed companies, with a daily trading volume of about 389,584 shares. This number of listed stocks increased to 91 as of December 31,2006 , with the trading volume rising to approximately $2,411,541$ shares per day. 
(Augmented Dickey-Fuller - ADF) shows that the CSAD time-series are stationary for all markets and hence no further test needs to be employed. Besides, the Jarque-Bera test also indicates normality for the four time-series at the 1 and 5\% levels.

Table 1

Descriptive statistics of CSAD variables

\begin{tabular}{|c|c|c|c|c|c|}
\hline Statistics & & IN_CSAD & MA_CSAD & PH_CSAD & VI_CSAD \\
\hline Sample period & & $\begin{array}{c}25 / 01 / 1997- \\
28 / 08 / 2013\end{array}$ & $\begin{array}{l}14 / 04 / 1992- \\
28 / 08 / 2013\end{array}$ & $\begin{array}{l}16 / 12 / 2003- \\
28 / 08 / 2013\end{array}$ & $\begin{array}{l}10 / 01 / 2007- \\
28 / 08 / 2013\end{array}$ \\
\hline Number of stocks & & 27 & 30 & 26 & 30 \\
\hline Minimum & & - & - & 0.00459 & - \\
\hline Maximum & & 0.16714 & 0.09004 & 0.06921 & 0.12641 \\
\hline Mean & & 0.02277 & 0.01222 & 0.01584 & 0.01495 \\
\hline Std.dev & & 0.01533 & 0.00656 & 0.00696 & 0.00786 \\
\hline Skewness & & 2.61297 & 3.14584 & 2.20258 & 3.42386 \\
\hline Kurtosis & & 13.14336 & 22.74182 & 12.09298 & 35.31151 \\
\hline Jarque-Bera & & $21,857 * * *$ & $94,344 * * *$ & $8,388 * * *$ & $8 * *$ \\
\hline \multirow{4}{*}{$\begin{array}{l}\text { Serial auto- } \\
\text { correlation at lag }\end{array}$} & 1 & 0.701 & 0.729 & 0.467 & 0.243 \\
\hline & 5 & 0.574 & 0.582 & 0.309 & 0.176 \\
\hline & 15 & 0.568 & 0.526 & 0.247 & 0.091 \\
\hline & 20 & 0.527 & 0.491 & 0.239 & 0.106 \\
\hline ADF test & & $-4.8295^{* * *}$ & $-6.9393 * * *$ & $-9.0379 * * *$ & $-9.6892 * * *$ \\
\hline
\end{tabular}

Notes: The table presents the descriptive statistics on the four sample markets' CSADs, including estimates of their skewness, kurtosis, normality and unit root tests.

$* * *, * *$ and $*$ represent statistical significance at the 1,5 and $10 \%$ levels, respectively.

\subsection{Estimates of herd behaviour}

Table 2 shows the regression results of the models adopted from Chang et al. (2000) for the entire period, the pre-crisis period and the during-crisis period, respectively. For the entire period, the figures show that the coefficient $\gamma_{2}$ is negative and statistically significant at the $1 \%$ level in the cases of Indonesia, Malaysia and Vietnam, implying the existence of herding in these three stock markets. However, results for the Philippines exhibit a negative coefficient for $\gamma_{2}$, which, nevertheless, is insignificant. Therefore, herd behaviour could not be confirmed for the Philippines' market. Besides, the regression results for the pre-crisis period indicate the existence of herding in Indonesia and Malaysia, whereas herding is observed only in Malaysia during the crisis period. No evidence of herding is reported in the Philippines' market during the two periods. 
To control for the robustness of our results, we further investigate the presence of herding in both up and down markets, and the results are displayed in Table 3. During the pre-crisis period, the coefficients $\gamma_{2}$ of Indonesia and Malaysia are negative and statistically significant at the $1 \%$ level during both up and down markets. During the crisis period, when the market is up, Indonesia maintains a negative coefficient $\gamma_{2}$, which is statistically insignificant, indicating the absence of herd behaviour (which is confirmed also during down markets). In the case of Malaysia, a negative $\gamma_{2}$ is also found in up and down markets. However, it is only during down markets that the coefficient is significant. Vietnam's stock market displays strong evidence of herding during rising markets, but no sign of herding is found in declining markets. Besides, the results for the Philippines' market indicate the absence of herding in both market scenarios.

\section{Table 2}

Estimates of herding behaviour in the four markets

\begin{tabular}{|c|c|c|c|c|c|}
\hline Markets/Periods & Constant & $\left|R_{m, t}\right|$ & $\mathrm{R}_{\mathrm{m}, \mathrm{t}}^{2}$ & Adj. $\mathrm{R}^{2}$ & DW \\
\hline \multirow{2}{*}{ Indonesia } & 0.0142 & $0.5990 * * *$ & $-0.6858 * * *$ & 0.3588 & 0.9405 \\
\hline & 45.1425 & 25.5216 & -2.8040 & & \\
\hline \multirow{2}{*}{ Pre-crisis } & 0.0158 & $0.7585 * * *$ & $-1.6628 * * *$ & 0.4103 & 1.0884 \\
\hline & 34.8777 & 23.9447 & -5.2734 & & \\
\hline \multirow{2}{*}{ Crisis } & 0.0132 & $0.2047 * * *$ & $1.1643 * * *$ & 0.3295 & 1.1299 \\
\hline & 53.9688 & 9.8830 & 4.8008 & & \\
\hline \multirow{2}{*}{ Malaysia } & 0.0083 & $0.5065 * * *$ & $-0.7036^{* * *}$ & 0.5553 & 1.1689 \\
\hline & 96.4842 & 57.7756 & -9.6550 & & \\
\hline \multirow{2}{*}{ Pre-crisis } & 0.0092 & $0.4909 * * *$ & $-0.6427 * * *$ & 0.5745 & 1.2576 \\
\hline & 84.9029 & 48.1066 & -7.9922 & & \\
\hline \multirow{2}{*}{ Crisis } & 0.0066 & $0.4688 * * *$ & $-1.3446 * * *$ & 0.4333 & 1.0701 \\
\hline & 55.5989 & 24.0836 & -2.9717 & & \\
\hline \multirow{2}{*}{ Philippines } & 0.0121 & $0.3426 * * *$ & -0.0455 & 0.2977 & 1.2954 \\
\hline & 54.5132 & 14.9284 & -0.1263 & & \\
\hline \multirow{2}{*}{ Pre-crisis } & 0.0152 & $0.4606 * * *$ & -0.4425 & 0.3172 & 1.7392 \\
\hline & 20.2950 & 6.6156 & -0.4411 & & \\
\hline \multirow{2}{*}{ Crisis } & 0.0117 & $0.2913 * * *$ & -0.1357 & 0.3197 & 1.2047 \\
\hline & 62.8125 & 14.8006 & -0.4251 & & \\
\hline \multirow{2}{*}{ Vietnam } & 0.0137 & $0.1584 * * *$ & $-3.0363 * * *$ & 0.0054 & 1.5371 \\
\hline & 33.2497 & 3.1808 & -2.7040 & & \\
\hline
\end{tabular}

Notes: This table reports the regression results of the following equation:

$$
\begin{aligned}
& C S A D_{t}=\alpha+\gamma_{1}\left|R_{m, t}\right|+\gamma_{2}\left(R_{m, t}\right)^{2}+\varepsilon_{t} \\
& * * *, * * \text { and } * \text { represent statistical significance at the } 1,5 \text { and } 10 \% \text { levels, respectively. }
\end{aligned}
$$




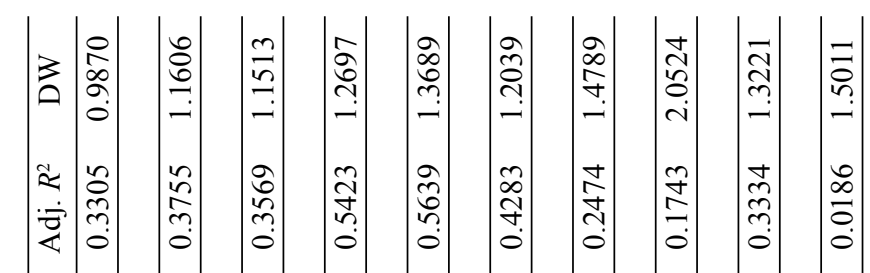

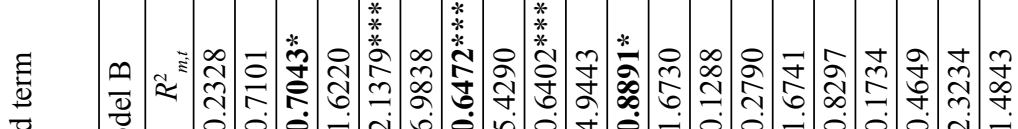

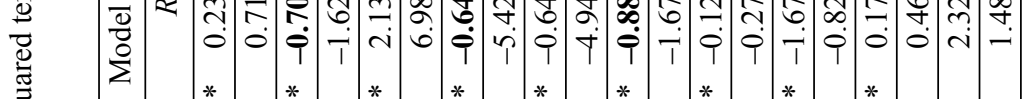

疍

롱

छँّ

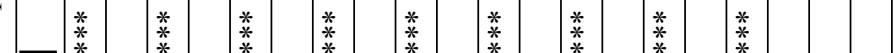

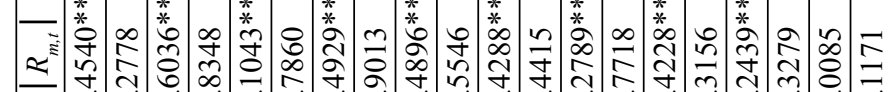

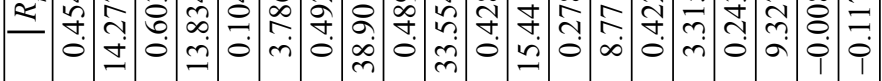

$\Xi \frac{0}{0}$

పี

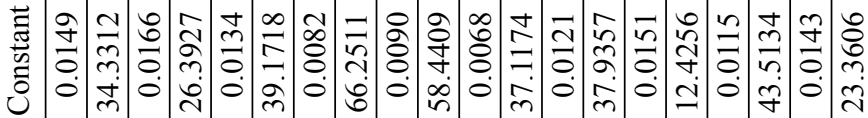

.

离跣

n

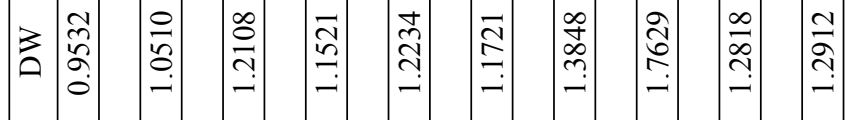

¿

苛

in

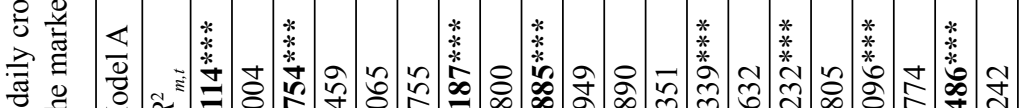

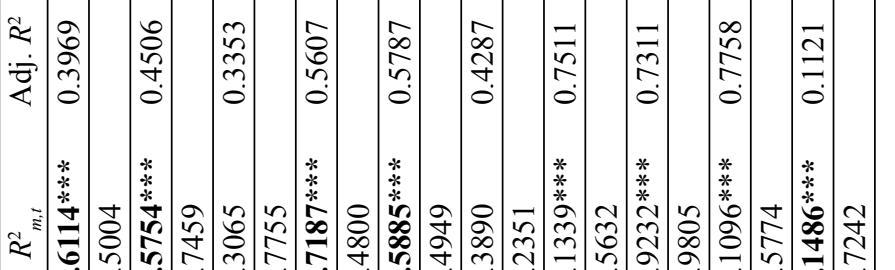

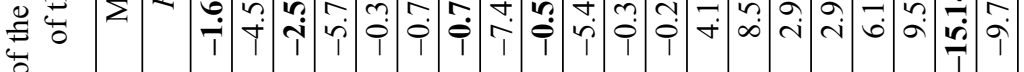

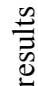

.0

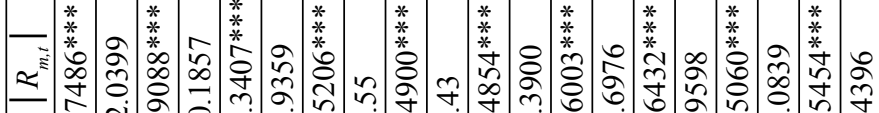

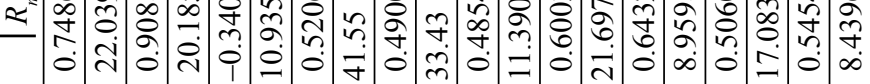

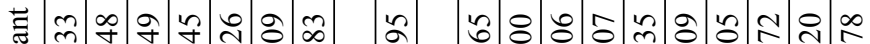

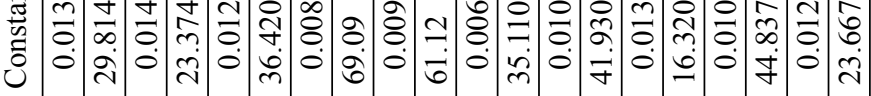

$\frac{n}{0}$
$\frac{0}{0}$
$\frac{0}{0}$
$\frac{0}{0}$
$\frac{0}{\pi}$
$\frac{\pi}{\Sigma}$
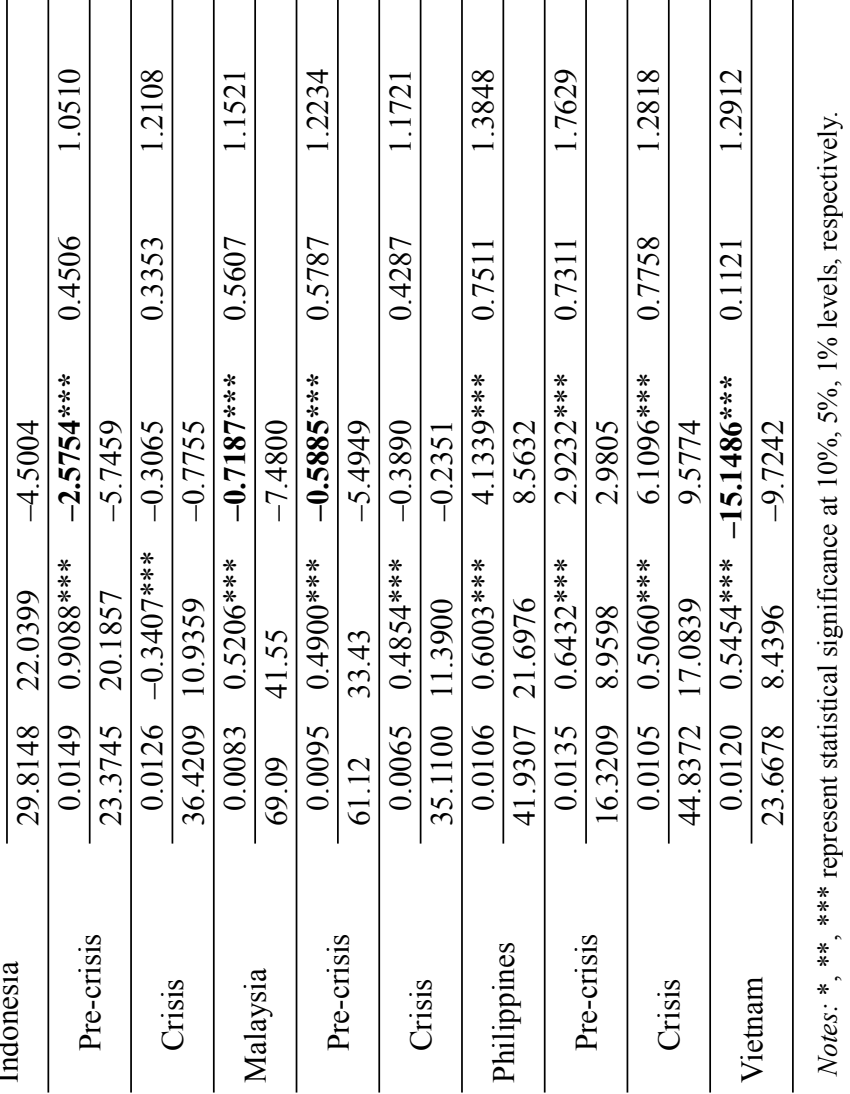
As displayed in Table 1, the time-series of our sample CSADs have high autocorrelation at different lags $(1,5,10$ and 20). Besides, the results presented in Tables 2 and 3 also show that the Durbin-Watson test statistics are in most cases below 1.5, indicating strong positive autocorrelation. Therefore, to improve the regressions' outcome, equations (3a) and (3b) were estimated and the results are exhibited in Tables 4 and 5, respectively.

Tables 4 and 5 also present a confirmation of herding in Malaysia's equity market during up and down markets in both sub-periods. Especially, during pre-crisis period, coefficient $\gamma_{2}$ and $\gamma_{3}$ are simultaneously significantly negative, indicating extremely strong degree of herding in Malaysia. In the Vietnamese market, the coefficient $\gamma_{2}$ is significantly negative only for up markets $\left(\gamma_{2}=-16.60\right)$ at the $1 \%$ level, together with a negative sum of $\gamma_{2}+\gamma_{3}$, indicating a strong degree of herd behaviour. Interestingly, the estimations for the Philippines with regression equation using a 1-day lag of the dependent variable $\left(\mathrm{CSAD}_{t}\right)$ and the independent

Table 4

Estimates of herding behaviour in the four markets

\begin{tabular}{|c|c|c|c|c|c|c|c|}
\hline $\begin{array}{l}\text { Markets/ } \\
\text { Periods }\end{array}$ & Constant & $\left|R_{m, t}\right|$ & $R_{m, t}^{2}$ & $R_{m, t-1}^{2}$ & $\mathrm{CSAD}_{t-1}$ & Adj. $R^{2}$ & DW \\
\hline \multirow{2}{*}{ Indonesia } & 0.0045 & $0.3522 * * *$ & 0.1065 & $-0.3256 * * *$ & $0.5758 * * *$ & 0.6300 & 2.3359 \\
\hline & 14.8660 & 19.1359 & 0.5710 & -3.0997 & 49.4222 & & \\
\hline \multirow{2}{*}{ Pre-crisis } & 0.0060 & $0.4974 * * *$ & $-0.7232 * * *$ & 0.0706 & $0.4959 * * *$ & 0.6234 & 2.2613 \\
\hline & 12.8550 & 18.9151 & -2.8544 & 0.5028 & 31.9074 & & \\
\hline \multirow{2}{*}{ Crisis } & 0.0064 & $0.1238 * * *$ & $1.3383 * * *$ & $-0.4085 * * *$ & $0.4881 * * *$ & 0.5181 & 2.2965 \\
\hline & 18.1157 & 6.9387 & 6.4648 & -3.2593 & 23.3520 & & \\
\hline \multirow{2}{*}{ Malaysia } & 0.0035 & $0.3277 * * *$ & $-0.2229 * * *$ & $-0.3374 * * *$ & $0.5059 * * *$ & 0.7258 & 2.2234 \\
\hline & 31.5741 & 43.1793 & -3.6450 & -7.4600 & 53.8941 & & \\
\hline \multirow{2}{*}{ Pre-crisis } & 0.0043 & $0.3258^{* * *}$ & $-0.2211 * * *$ & $-0.2561^{* * *}$ & $0.4725^{* * *}$ & 0.7212 & 2.2076 \\
\hline & 28.7129 & 35.6843 & -3.1843 & -5.0848 & 40.4604 & & \\
\hline \multirow{2}{*}{ Crisis } & 0.0027 & $0.3360 * * *$ & -0.1131 & $-1.7574 * * *$ & $0.5127 * * *$ & 0.6292 & 2.2550 \\
\hline & 15.9342 & 20.4400 & -0.3069 & -6.8248 & 28.6245 & & \\
\hline \multirow{2}{*}{ Philippines } & 0.0071 & $0.2739 * * *$ & 0.2471 & 0.0962 & $0.3557 * * *$ & 0.4199 & 2.1269 \\
\hline & 21.2793 & 12.9395 & 0.7541 & 0.5061 & 17.9961 & & \\
\hline \multirow{2}{*}{ Pre-crisis } & 0.0128 & $0.4397 * * *$ & -0.2654 & 0.4141 & $0.1203 * * *$ & 0.3340 & 1.9835 \\
\hline & 10.8647 & 6.3430 & -0.2665 & 0.7681 & 2.4620 & & \\
\hline \multirow{2}{*}{ Crisis } & 0.0062 & $0.2148^{* * *}$ & 0.0822 & $0.2670^{* *}$ & $0.4165^{* * *}$ & 0.4894 & 2.1724 \\
\hline & 20.1119 & 12.3603 & 0.2973 & 1.6112 & 19.8707 & & \\
\hline \multirow{2}{*}{ Vietnam } & 0.0100 & $0.1244 * * *$ & $-3.0241 * * *$ & $1.9476^{* * *}$ & $0.2371 * * *$ & 0.0771 & 2.1072 \\
\hline & 19.1612 & 2.5856 & -2.7791 & 5.4114 & 9.9986 & & \\
\hline
\end{tabular}

Notes: This table reports the regression results of CSADs based on the following equation:

$C S A D_{t}=\alpha+\gamma_{1}\left|R_{m, t}\right|+\gamma_{2}\left(R_{m, t}\right)^{2}+\gamma_{3}\left(R_{m, t-1}\right)^{2}+\gamma_{4} C S A D_{t-1}+\varepsilon_{t}$

$* * *$ and $* *$ represent statistical significance at the $1 \%$ and $5 \%$ levels, respectively. 
variable $\left(R_{m, l}\right)$ show a significantly negative coefficient $\left(\gamma_{3}=-3.8687\right)$ at the $1 \%$ level, but the value of $\gamma_{2}+\gamma_{3}$ is positive. Therefore, the existence of herding during the crisis period and when market is up cannot be confirmed.

In general, strong herd behaviour was found in Malaysia, Indonesia and Vietnam, both in the pre-crisis and crisis period, and in the upward and downward markets. However, in the Philippines the presence of herding is only documented when the market was up during crisis period. Chang et al. (2000) argue that the differences in herding among markets are significantly dependent on the quality of micro information disclosure. If a market is inefficient in information disclosure, investors will basically base their investment decisions on other sources as well as other investors' actions. Therefore, herding will be weaker or absent in a stock market if the quality of information disclosure is improved, with micro information being accessible to all investors. Relying on this argument, it is likely that a better information disclosure in the Philippines could be a reason explaining the weak degree of herding in this market. Particularly, we observe that to control its quality of information disclosure, the Philippines stock exchange (PSE) launched an online 24/7 disclosure system (ODiSy) in 2005. The system basically aims to improve the transparency of listed companies and also to ensure full, fair, timely and accurate disclosure of information from all listed companies. Hence, Filipino investors could be more informed and form their own investment strategies using the information, resulting in the absence of herding in this market.

With respect to the outcomes of the models, a noticeable high degree of herding was observed during rising markets in Vietnam. A possible explanation for this could be laid on a weak and inadequate regulatory framework in Vietnam's stock market as lately suggested by Tran - Truong (2011). This may prevent investors from approaching market-related and firm-specific information used in making investment decisions. As a result, investors may follow the actions of foreign investment funds or giant stockbrokers who are believed to have more information. Moreover, they argue that, similarly to other emerging markets, the operation of Vietnam's stock market was affected by the relatively heavy intervention of the government. Given those characteristics, investors were likely to trade based on market consensus and thus exhibit strong evidence of herding in this market.

Our findings also indicate that the confirmation of herding in the four markets vary under up and down market condition. This is consistent with the assumption that herding behaviour presents an asymmetric reaction on days when the market is up vis-à-vis days when the market is down (Tan et al. 2008; Chiang Zheng 2010). Chiang et al. (2013) debate that an asymmetry in herding between rising and falling markets may be caused by the flow of positive and negative information, and investors tend to herd when the market is trending up in most of the cases. Because of the up market, investors are likely to be more optimistic 


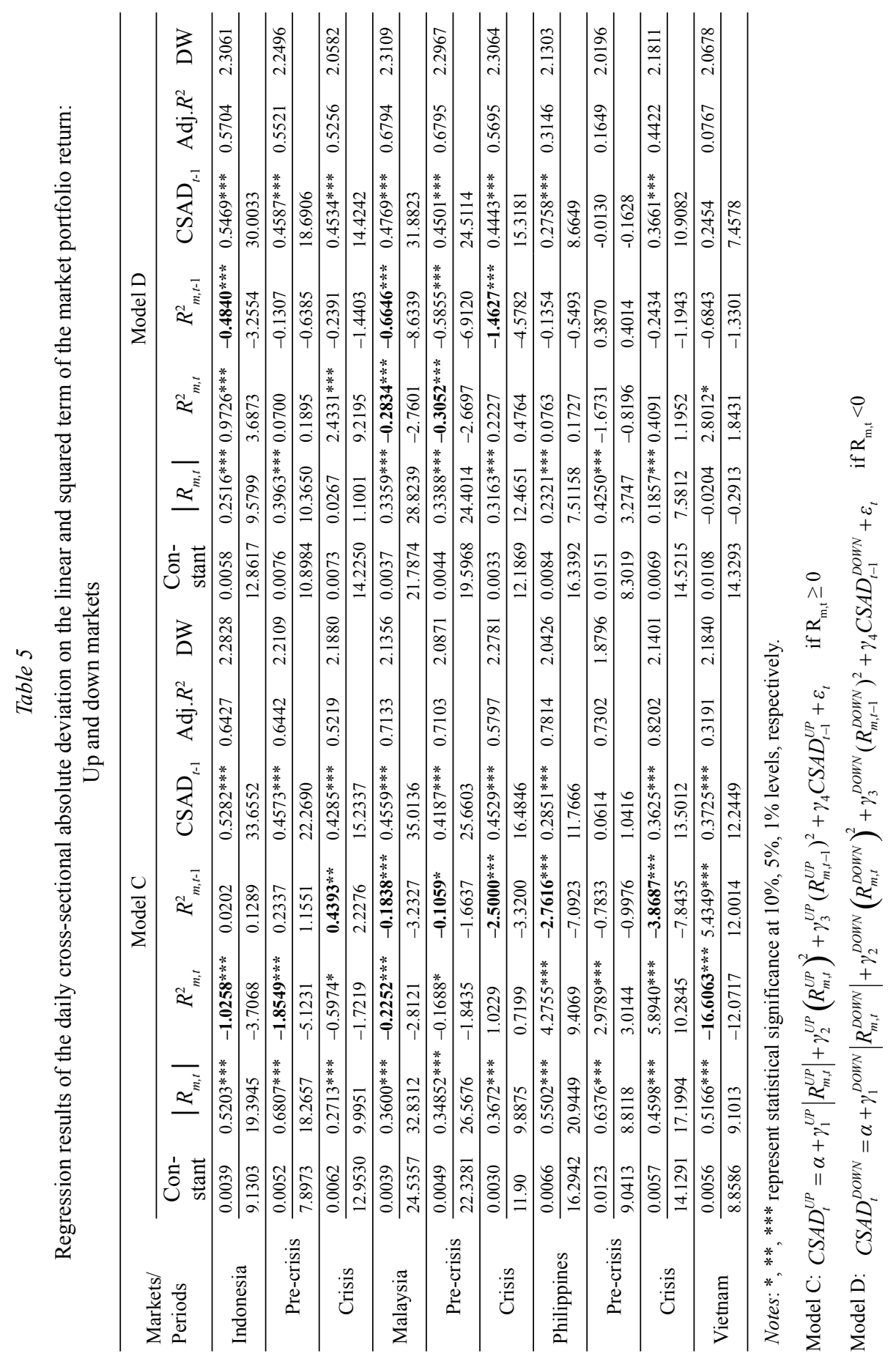




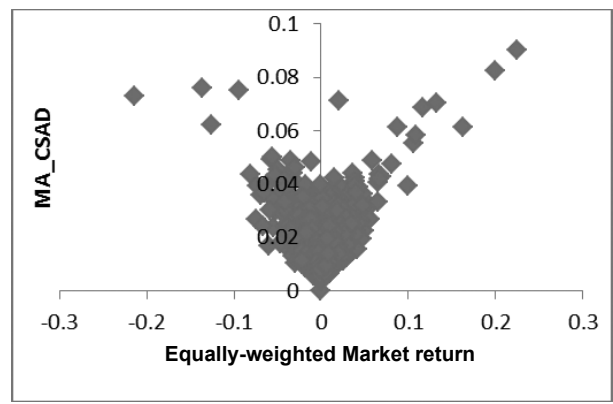

(a)

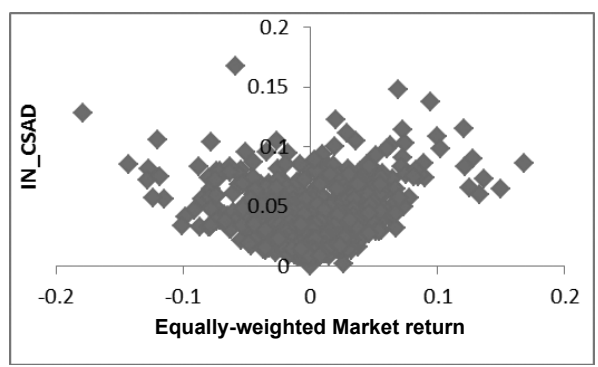

(b)

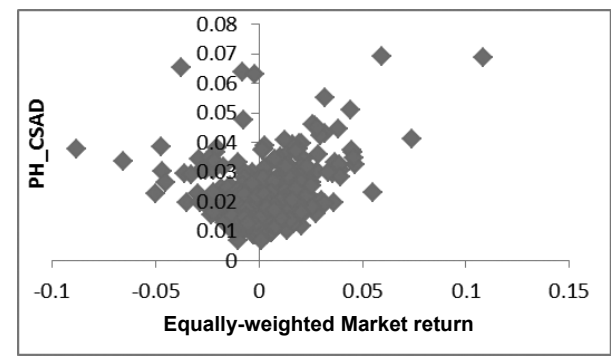

(c)

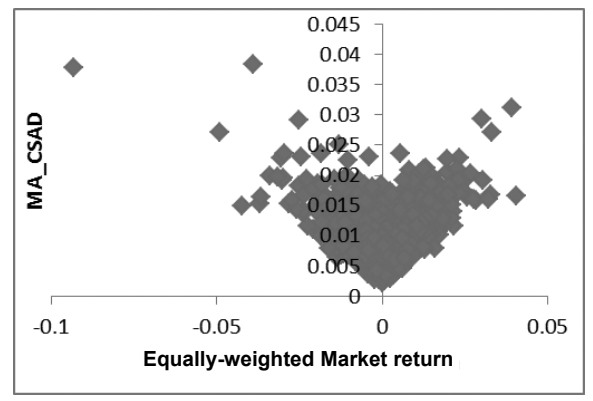

(a’)

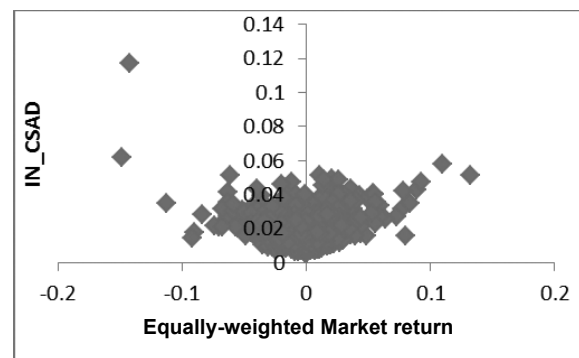

(b')

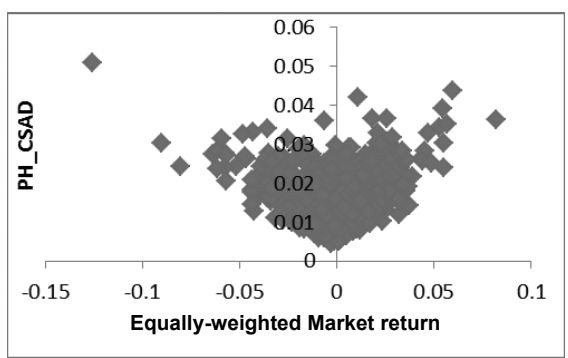

(c')

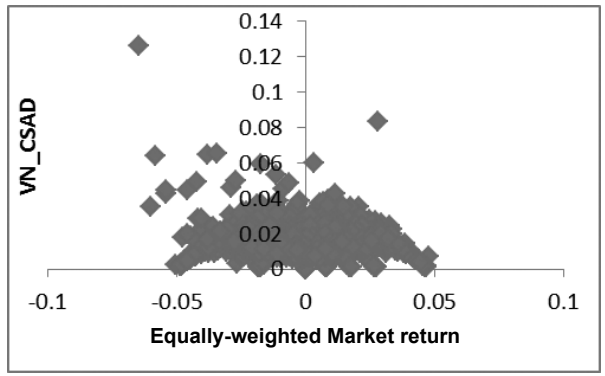

(d)

Figure 1. Relationship between the daily cross-sectional absolute deviation $\left(\mathrm{CSAD}_{t}\right)$ and the corresponding equally weighted market return $\left(R_{m, l}\right)$ for Malaysia (a, a'), Indonesia ( $\mathrm{b}, \mathrm{b}$ '), the Philippines (c, c'), and Vietnam (d), during the pre-crisis and crisis period, respectively. 
on positive market and firm-related information, which may significantly cause rational herd behaviour during this time. Conversely, during down market, negative information may intentionally be limited for the public in the market, causing less rational herding in the down market. According to Chiang et al. (2013), another possibility is that investors have a strong belief that the government will intervene when markets are decreased significantly, and are thus less likely to herd in falling markets.

The inconsistencies of herding in the four equity markets can be simply observed by plotting the CSAD measure for each day and the corresponding equally-weighted market return. Particularly, if the CSAD-market relation exhibits a non-linearity, the existence of herding can be confirmed, while a linear relationship would indicate the absence of herding. Figure 1 shows the relationship between the daily cross-sectional absolute deviation $\left(\mathrm{CSAD}_{t}\right)$ and the corresponding equally weighted market return $\left(R_{m, l}\right)$ for the four markets during the pre-crisis and crisis period. Focusing on the dispersion of CSAD-market returns, we observe a linear relationship between CSAD-market returns in the Philippines, Malaysia, and Indonesia in both sub-periods, whereas a non-linear relationship is strongly exhibited for Vietnam during the crisis period, implying the presence of herding in this market.

\section{CONCLUSION AND IMPLICATIONS}

This study investigates empirically the presence of herd behaviour in four equity markets, namely Vietnam, the Philippines, Malaysia, and Indonesia. In Vietnam's market, the results strongly indicate the presence of herding during up markets. However, when the market was down, no evidence of herding was observed. This is consistent with the findings of Kallinterakis (2007) and Tran - Truong (2011), who also report a high degree of herding in Vietnam. We also discovered evidence of herding in Malaysia and Indonesia, which is in line with the evidence from previous studies by Chiang - Zheng (2011) and Chiang et al. (2013). Further examination of herding in both up and down markets during our two sub-periods reveals that herding is absent when the Indonesian market is down, whereas herding is observed in the Malaysian market during the pre-crisis period. However, during the crisis period, herding in the Malaysian market is only exhibited when the market is downward. No evidence of herding is found in the Philippines stock market in either periods. Besides, the inconsistence of herding is documented when using 1-day lags variables that strongly indicate that the level of equity return dispersions is significantly affected by the return (up or down) of the previous trading day. 
The findings of herding presented here have important investment and policy implications. Policy makers should improve the efficient information disclosure and prevent inside traders in emerging stock markets. Strong herding may drive stock prices far from their intrinsic value, leading to mispricing in the market.

Although the study provides interesting findings regarding herd behaviour in Southeast Asian financial markets, there are some limitations that are beyond the scope of this paper, but they merit more attention. For example, the study only considers stocks included in the four markets' blue-chip indices, not making use of the universe of listed stocks in each market, which could allow for the opportunity of testing for the existence of size or industry effects. Besides, the exclusion of Thailand's market due to unavailable data constitutes another shortcoming of the study.

\section{REFERENCES}

Bhaduri, S. N. - Mahapatra, S. D. (2013): Applying an Alternative Test of Herding Behavior: A Case Study of Indian Stock Market. Journal of Asian Economics, 25: 43-52.

Chang, E. C. - Cheng, J. W. - Khorana, A. (2000): An Examination of Herd Behavior in Equity Markets: An International Perspective. Journal of Banking and Finance, 24: 1651-1679.

Chiang, T. C. - Li, J. - Tan, L. (2010): Empirical Investigation of Herding Behavior in Chinese Stock Markets: Evidence from Quantile Regression Analysis. Global Finance Journal, 21: 111-124.

Chiang, T. C. - Li, J. - Tan, L. - Nelling, E. (2013): Dynamic Herding Behavior in Pacific-Basin Markets: Evidence and Implication. Forthcoming in Multinational Finance Journal. Available at SSRN:http://ssrn.com/abstract=2278979

Chiang, T. C. - Zheng, D. (2010): An Empirical Analysis of Herd Behavior in Global Stock Markets. Journal of Banking and Finance, 34: 1911-1921.

Christie, W. G. - Huang, R. D. (1995): Following the Pied Piper: Do Individual Returns Herd around the Market? Financial Analysts Journal, 51: 31-37.

Demirer, R. - Kutan, A. M. (2006): Does Herding Behavior Exist in Chinese Stock Market? Journal of International Financial Markets, Institutions and Money, 16: 123-142.

Demirer, R. - Kutan, A. M. - Chen, C. D. (2010): Do Investors Herd in Emerging Stock Markets?: Evidence From The Taiwanese Market. Journal of Economic Behavior and Organization, 76: 283-295.

Duasa, J. - Kassim, S. (2008): Herd Behavior in Malaysian Capital Market: An Empirical Analysis. Munich Personal RePEc Archive, MPRA Paper No. 13303:1-18.

Fama, E. F. (1970): Efficient Capital Markets: A Review of Theory and Empirical Work. Journal of Finance, 25(2): 383-417.

Furuoka, F. (2013): Population and Economic Development in Indonesia: A Revisit with New Data and Methods. Acta Oeconomica, 63(4): 451-467.

Iihara, Y. - Kato, H. K. - Tokunaga, T. (2001): Investors' Herding on The Tokyo Stock Exchange. International Review of Finance, 2: 71-98.

Juan, Y. - Chuanchan, M. - William, P. H. (2014): Investor Herding Behavior of Chinese Stock Market. International Review of Economics and Finance, 29: 12-29. 
Kallinterakis, V. (2007): Herding and the Thin Trading Bias in a Start-up Market: Evidence from Vietnam. Working paper, Durham University, Business School.

Laih, Y. W. - Liau, Y. S. (2013): Herding Behavior during the Subprime Mortgage Crisis: Evidence from Six Asia-Pacific Stock Markets. International Journal of Economics and Finance, 5: 71-84.

Newey, W. K. - West, K. (1987): A Simple Positive Semi-Definite, Heteroskedasticity and Autocorrelation Consistent Covariance Matrix. Econometrica, 55: 703-708.

Nofsinger, J. R. - Sias, R. W. (1999): Herding and Feedback Trading by Institutional and Individual Investors. The Journal of Finance, 54: 2263-2295.

Rajan, R. G. (1994): Why Credit Policies Fluctuate: A Theory and some Evidence. Quarterly Journal of Economics, 436: 399-442.

Scharfstein, D. S. - Stein, J. C. (1990): Herd Behavior and Investment. The American Economic Review, 80: 465-479.

Tan, L. - Chiang, T. C. - Mason, J. - Nelling, E. (2008): Herding Behavior in Chinese Stock Markets: An Examination of A and B Shares. Pacific-Basin Finance Journal, 16: 61-77.

Tran, N. M. - Truong, H. H. (2011): Herding Behavior in an Emerging Stock Market: Empirical Evidence from Vietnam. Research Journal of Business Management, 5(2): 51-76.

Vaughan, G. M. - Hogg, M. A. (2005): Introduction to Social Psychology. Australia Education Pearson. 